
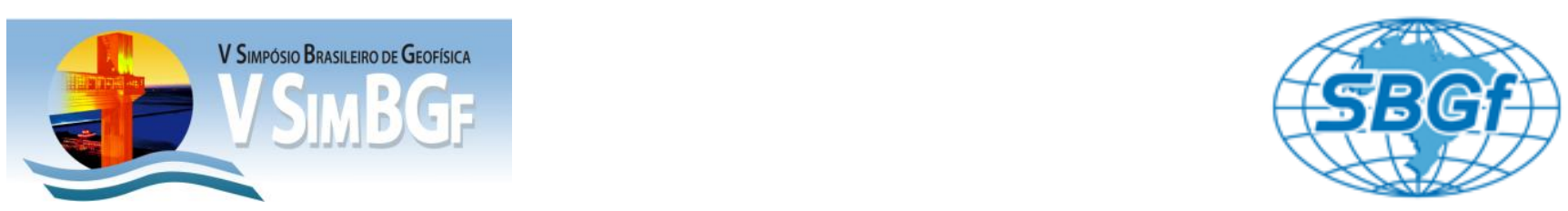

\title{
PROCESSAMENTO DE DADOS DE SONDAGENS MAGNETOTELÚRICAS COLETADOS NA PROVÍNCIA BORBOREMA, REGIÃO NORDESTE DO BRASIL
}

Melissa Tami Makibara* - melissa.makibara@usp.br (IAG / USP)

Ícaro Vitorello (LAC / CTE / INPE, Orientador)

Mauricio de Souza Bologna (IAG / USP, Co-orientador)

Copyright 2012, SBGf - Sociedade Brasileira de Geofísica

Este texto foi preparado para a apresentação no V Simpósio Brasileiro de Geofísica, Salvador, 27 a 29 de novembro de 2012. Seu conteúdo foi revisado pelo Comitê Técnico do V SimBGf, mas não necessariamente representa a opinião da SBGf ou de seus associados. É proibida a reprodução total ou parcial deste material para propósitos comerciais sem prévia autorização da SBGf.

\section{Resumo}

A Província Borborema possui uma história geológica complexa cuja origem e evolução tectônica têm sido baseadas principalmente por estudos geológicos e geocronológicos de amostras em superfície. Porém, há pouco conhecimento a respeito da composição e estrutura profunda da litosfera dessa província. Este projeto tem como objetivo mapear a condutividade na região e contribuir para o melhor conhecimento da província através de processamento e análise de dados magnetotelúricos (MT). Para isso, é utilizada uma técnica robusta e, após algumas etapas, são feitos gráficos de resistividade aparente e fase em função do período e, através da transformada de Nibblet - Bostick, em função da profundidade. Nesta etapa do projeto foi realizado o processamento e reprocessamento (com utilização de pré-seleção) de dados MT em 13 estações do perfil 1, como vemos na figura 1, situadas nas vizinhanças do lineamento Sobral-Pedro II. Da análise das curvas de resistividade aparente e fase das estações e da transformada de Nibblet - Bostick é possível verificar uma descontinuidade na resistividade, pois a região superior (mais rasa) é resistiva em relação à região mais profunda.

\section{Introdução}

O processamento de dados é realizado com uma técnica robusta que representa no estado da arte do processamento MT. Primeiramente são calculados os coeficientes de Fourier e são combinados os auto espectros e espectros cruzados para que sejam calculadas as impedâncias MT e, a partir delas, calculadas as resistividades aparentes e fases em todas as estações. Então, é possível plotar os gráficos e visualizar as resistividades aparentes e fases em função do período. Após esta importante etapa, notou-se a descontinuidade na curva de resistividade aparente na faixa de frequência de $10^{-4}$ até $10^{-2} \mathrm{~Hz}$. No intuito de melhorar as respostas obtidas, toda a etapa de processamento foi repetida, desta vez utilizando uma préseleção dos dados baseada na coerência entre os sinais elétricos e magnéticos. Ou seja, se um determinado ponto tem uma impedância calculada que está abaixo de uma porcentagem determinada de acordo com a coerência dos sinais, ele é ignorado. Assim, os resultados podem sofrer alguma melhora nas curvas de resistividade aparente e fase, principalmente na região mais rasa (frequências mais altas) e na região em torno de $1 \mathrm{~Hz}$, como veremos a seguir. Este trabalho discutirá os resultados do processamento robusto de 13 estações MT situadas nas vizinhanças do lineamento Sobral-Pedro II, que tem sido considerado uma extensão do lineamento Trans - Brasiliano no Estado do Ceará, como vemos na figura 1:

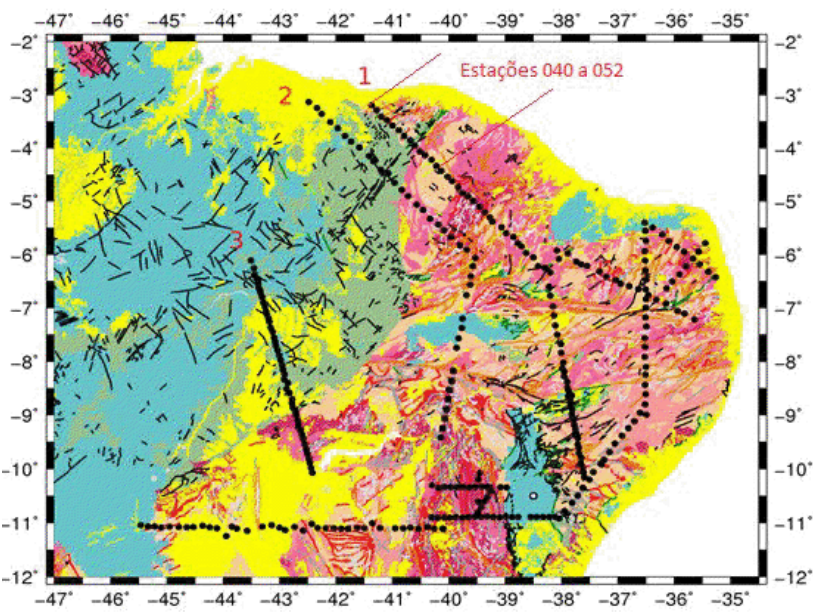

Figura 1: Perfis MT da Província Borborema com foco nas estações processadas do perfil 1.

\section{Metodologia}

O método geofísico MT foi proposto inicialmente por Tikhonov (1950) e Cagniard (1953). É um método passivo, que utiliza as variações do campo geomagnético como fonte de sinal para mapear a condutividade elétrica do interior da crosta e do manto superior terrestre. Para isto, são realizadas medições na superfície da Terra dos campos elétrico e magnético em duas componentes horizontais ortogonais. Em estudos regionais, a componente vertical do magnético é também usualmente medida. O arranjo esquemático do método MT é mostrado na figura 2. 


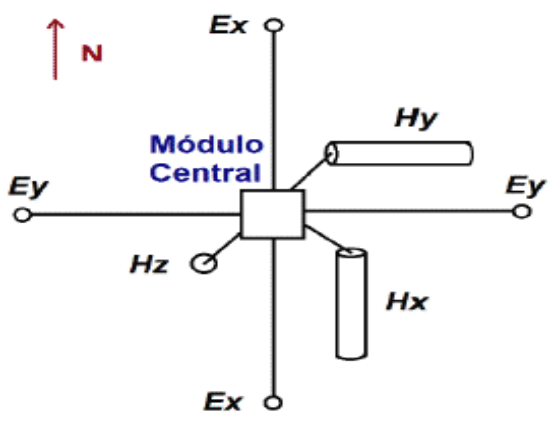

Figura 2: Ilustração de sondagem MT (vista em planta). Geralmente N é o norte magnético.

\section{Resultados}

A primeira etapa do processamento de dados consiste em obter os auto espectros e espectros cruzados das componentes dos campos elétrico e magnético a partir dos coeficientes de Fourier das séries temporais. A partir da relação desses espectros, são determinadas as impedâncias em função da frequência, ou seja, o tensor MT. Então, é possível representar graficamente a resistividade aparente e fase através de curvas em função do período (vide figura 3).

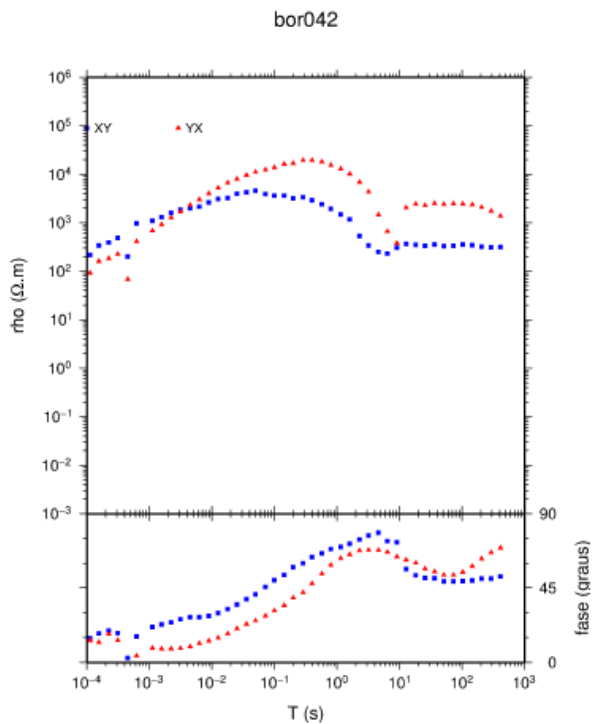

Figura 3: curva de resistividade aparente e fase da estação 042 em função do período.

O passo seguinte é tentar melhorar tais descontinuidades através, primeiramente, de uma pré-seleção dos dados levando em conta a coerência dos sinais. Então, dando continuidade ao processamento, novamente foram feitos os gráficos de resistividade e fase de cada estação. $\mathrm{Na}$ figura 4 podemos ver o exemplo da estação 042:

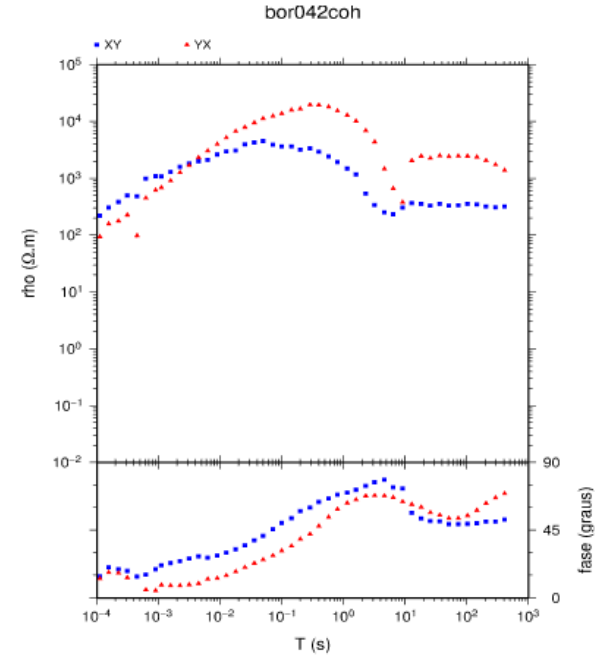

Figura 4: gráfico de resistividade aparente e fase da estação 042 com pré-seleção de dados por coerência.

Uma prévia análise da penetração do sinal em cada estação foi feita usando a transformada Niblett-Bostick (Jones, 1983). Esta se baseia no princípio da penetração pelicular (skin depth) para converter as respostas MT (resistividade aparente e fase) em perfis de resistividade em função da profundidade. A vantagem deste procedimento é a extrema simplicidade os cálculos envolvidos, que depende apenas dos próprios dados. Então foram feitos os gráficos de resistividade aparente, já com a pré-seleção por coerência, em função da profundidade, como se vê na figura 5 .

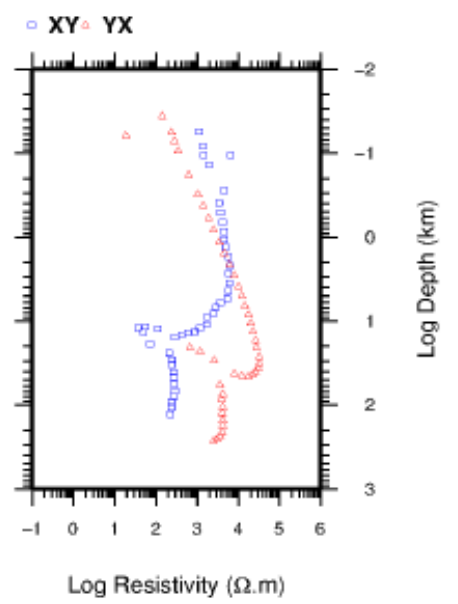

Figura 5: Tranformada de Niblett-Bostick da estação 042 - dados com pré-seleção por coerência.

\section{Conclusões}

Como podemos verificar nas figuras que mostram as curvas de resistividade aparente e fase de cada estação, a banda A parece ser sempre mais ruidosa. No entanto, ela traz informações muitos rasas (da ordem algumas dezenas de metros). Em períodos mais longos, que são 
mais importantes para este trabalho, os dados são consistentes. Vê- se que o meio é relativamente resistivo. As resistividades aparentes mesmo em períodos longos são da ordem de 100-1000 ohm-m. Também, observa-se que o meio em torno dessas estações é heterogêneo, uma vez que as fases xy e yx são distintas em todas as 13 estações processadas.

Do reprocessamento de dados, é possível ver melhorias na continuidade das curvas de resistividade aparente e fase, principalmente em regiões que representam frequências maiores, por serem mais rasas e o ruído ser considerável. Algumas estações permaneceram como antes, pois nem sempre é possível obter com sucesso a melhoria de dados, como desejado. Porém, este é apenas um dos métodos que podemos aplicar para a possível melhoria dos dados.

Da transformada de Niblett-Bostick, vemos que a região superior é resistiva e entre 3 e $10 \mathrm{~km}$ de profundidade, ocorre uma descontinuidade, onde a região passa a ser condutiva

\section{Agradecimentos}

Este trabalho foi desenvolvido com apoio do PIBIC/CNPq (Processo: 105494/2011-9). Os autores agradecem à toda equipe de campo e laboratório do Grupo de Geomagnetismo do INPE, e ao Departamento de Geofísica do IAG-USP.

\section{Referências}

Brito Neves, B. B., Santos, E. J., Van Schmus, W. R., 2000, Tectonic histoty of the Borborema Province, northeastern Brazil. In: Cordani, U. G, Milani, E. J., Thomaz-Filho, A., Campos, D. A. (Ed.), Tectonic Evolution of South America, p.151-182.

Cagniard, L., 1953, Basic theory of the magneto-telluric method of geophysical prospecting. Geophysics, 18, 605635.

Egbert, G.D., 1997. Robust multiple-station magnetotelluric data processing. Geophysical Journal International, 130, 475-496.

Egbert, G.D., 1999. Transfer Function Estimation for Electromagnetic Induction Studies: Evolution and Stateof-the-Art.

Jones, A.G., 1983. On the equivalence of the Niblett and Bostick transformations in the magnetotelluric method. Journal of Geophysics, 53, 72-73.

Nunes, H. O., 2007, Imageamento das estruturas geoelétricas da litosfera na Província Borborema pelo método magnetotelúrico, Trabalho de graduação II, USP - SP.

Tikhonov, A. N., 1950, On determining electrical characteristics of the deep layers of the earth's crust. Doklady Akademii Nauk SSSR, 73, 295- 297. 